\title{
Front Matter: Volume 11339
}

, "Front Matter: Volume 11339," Proc. SPIE 11339, AOPC 2019: Quantum Information Technology, 1133901 (18 December 2019); doi:

$10.1117 / 12.2564868$

SPIE. Event: Applied Optics and Photonics China (AOPC2019), 2019, Beijing, China 


\title{
PROCEEDINGS OF SPIE
}

\section{AOPC 2019: Quantum Information Technology}

\author{
Jianyu Wang \\ Chaoyang Lu \\ Sven Höfling \\ Editors
}

7-9 July 2019

Beijing, China

Sponsored by

Chinese Society for Optical Engineering (China)

Cosponsored by

SPIE

Organized by

Chinese Society for Optical Engineering (China)

Photoelectronic Technology Committee, Chinese Society of Astronautics (China)

Science and Technology on Low-light-level Night Vision Laboratory (China)

Science and Technology on Electro-Optical Information Security Control Laboratory (China)

Academy of Opto-Electronics of Electronics Technology of China (China)

Infrared and Laser Engineering (China)

Published by

SPIE

Volume 11339 
The papers in this volume were part of the technical conference cited on the cover and title page. Papers were selected and subject to review by the editors and conference program committee. Some conference presentations may not be available for publication. Additional papers and presentation recordings may be available online in the SPIE Digital Library at SPIEDigitallibrary.org.

The papers reflect the work and thoughts of the authors and are published herein as submitted. The publisher is not responsible for the validity of the information or for any outcomes resulting from reliance thereon.

Please use the following format to cite material from these proceedings:

Author(s), "Title of Paper," in AOPC 2019: Quantum Information Technology, edited by Jianyu Wang, Chaoyang LU, Sven Höfling, Proceedings of SPIE Vol. 11339 (SPIE, Bellingham, WA, 2019) Seven-digit Article CID Number.

ISSN: 0277-786X

ISSN: 1996-756X (electronic)

ISBN: 9781510634503

ISBN: 9781510634510 (electronic)

Published by

SPIE

P.O. Box 10, Bellingham, Washington 98227-0010 USA

Telephone +1 3606763290 (Pacific Time) · Fax + 13606471445

SPIE.org

Copyright @ 2019, Society of Photo-Optical Instrumentation Engineers.

Copying of material in this book for internal or personal use, or for the internal or personal use of specific clients, beyond the fair use provisions granted by the U.S. Copyright Law is authorized by SPIE subject to payment of copying fees. The Transactional Reporting Service base fee for this volume is $\$ 21.00$ per article (or portion thereof), which should be paid directly to the Copyright Clearance Center (CCC), 222 Rosewood Drive, Danvers, MA 01923. Payment may also be made electronically through CCC Online at copyright.com. Other copying for republication, resale, advertising or promotion, or any form of systematic or multiple reproduction of any material in this book is prohibited except with permission in writing from the publisher. The CCC fee code is 0277$786 \times / 19 / \$ 21.00$.

Printed in the United States of America by Curran Associates, Inc., under license from SPIE.

Publication of record for individual papers is online in the SPIE Digital Library.

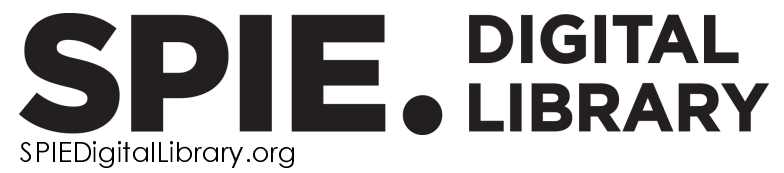

Paper Numbering: Proceedings of SPIE follow an e-First publication model. A unique citation identifier (CID) number is assigned to each article at the time of publication. Utilization of CIDs allows articles to be fully citable as soon as they are published online, and connects the same identifier to all online and print versions of the publication. SPIE uses a seven-digit CID article numbering system structured as follows:

- The first five digits correspond to the SPIE volume number.

- The last two digits indicate publication order within the volume using a Base 36 numbering system employing both numerals and letters. These two-number sets start with $00,01,02,03,04$, 05, 06, 07, 08, 09, OA, OB ... 0Z, followed by 10-1Z, 20-2Z, etc. The CID Number appears on each page of the manuscript. 


\title{
Contents
}

\author{
V Authors \\ vii Conference Committee \\ ix Introduction
}

QUANTUM INFORMATION TECHNOLOGY

1133902 The superposition invariance of unitary operators and maximally entangled state [1 1339-1]

1133903 Phase attack on reference pulses of continuous-variable quantum key distribution with real local oscillators [1 1339-2]

$1133904 \quad$ High speed comparator for single-photon avalanche photodiode [11339-4]

1133905 Quantum correlations over a large bandwidth in cascaded optical parametric system [11339-6]

1133906 Effect of atmosphere turbulence on the decay of orbital angular momentum entanglement state of light using the Hermite-Gaussian (HG) vortex beam encoding [1 1339-7]

1133907 Challenges and solutions of next-generation imager: CMOS single photon avalanche diode image sensor [1 1339-8]

1133908 Quantum color image encryption technology based on hyper-chaotic systems [1 1339-9]

1133909 Performance analysis of free space quantum key distribution with different wavelengths [1 1339-10]

11339 OA Quantum entanglement degrees of a two-level atom in the photonic crystals heat reservoir [11339-11]

$11339 \mathrm{OB} \quad$ Navigation applications of quantum microwave entanglement accomplished by electro-optomechanical converters [11339-12]

11339 OC Research on key problems of quantum state transformation based on cavity electro-optomechanical system [11339-13]

11339 OD Nonadiabatic robust pulses for creating superposition states in a resonant three-level system [1 1339-14] 
$11339 \mathrm{OE}$ Experimental observation of topologically protected bound states in two dimensional quantum walk [1 1339-15]

$11339 \mathrm{OF}$ Room-temperature high-speed InGaAs/InP single-photon detector with high detection efficiency [11339-16]

$113390 \mathrm{O}$ High sensitivity ranging photon-counting chirped amplitude modulation lidar [11339-17]

$11339 \mathrm{OH} \quad$ Study of in situ laser modification of InAs/GaAs quantum dots [11339-18]

11339 ol Quantum navigation ranging scheme based on dual-path entangled microwaves [11339-19]

$11339 \mathrm{0J}$ Spectral photon irradiance and spectral photon radiance standards for the calibration of photon-counting imagers [1 1339-20]

11339 OK The time domain waveform of dual-path entangled microwave signals [11339-21] 


\section{Authors}

Numbers in the index correspond to the last two digits of the seven-digit citation identifier (CID) article numbering system used in Proceedings of SPIE. The first five digits reflect the volume number. Base 36 numbering is employed for the last two digits and indicates the order of articles within the volume. Numbers start with 00, 01, 02, 03, 04, 05, 06, 07, 08, 09, 0A, 0B...0Z, followed by 10-1Z, 20-2Z, etc.

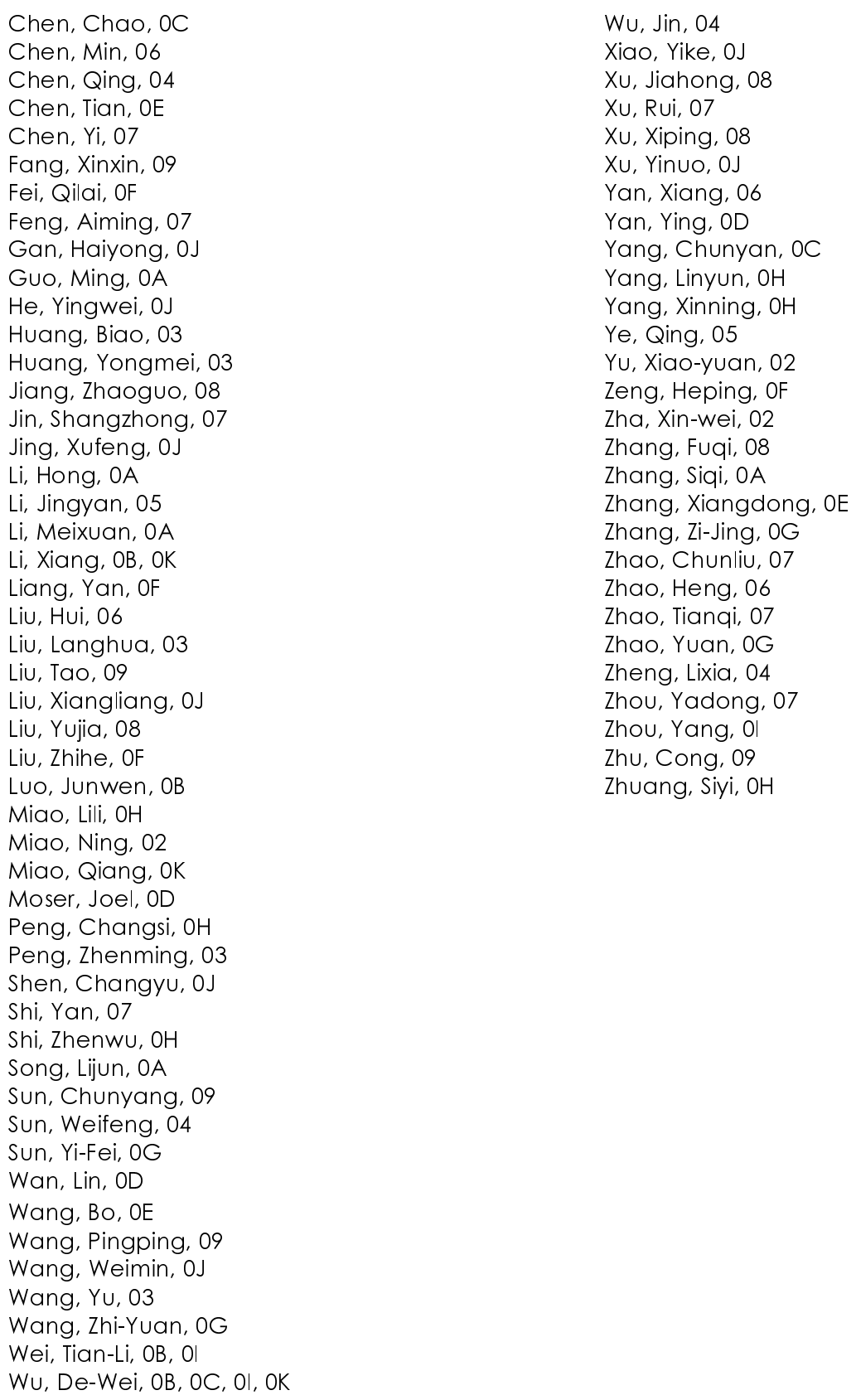

\author{
Wu, Jin, 04 \\ Xiao, Yike, $0 \mathrm{~J}$ \\ $\mathrm{Xu}$, Jiahong, 08 \\ $X \cup, R \cup i, 07$ \\ $X \cup, X i p i n g, 08$ \\ $X U, Y i n u o, 0 J$ \\ Yan, Xiang, 06 \\ Yan, Ying, OD \\ Yang, Chunyan, OC \\ Yang, Linyun, $\mathrm{OH}$ \\ Yang, Xinning, $\mathrm{OH}$ \\ Ye, Qing, 05 \\ Yu, Xiao-yuan, 02 \\ Zeng, Heping, OF \\ Zha, Xin-wei, 02 \\ Zhang, Fuqi, 08 \\ Zhang, Siqi, OA \\ Zhang, Xiangdong, OE \\ Zhang, Zi-Jing, $0 G$ \\ Zhao, Chunliu, 07 \\ Zhao, Heng, 06 \\ Zhao, Tianqi, 07 \\ Zhao, Yuan, OG \\ Zheng, Lixia, 04 \\ Zhou, Yadong, 07 \\ Zhou, Yang, 01 \\ Zhu, Cong, 09 \\ Zhuang, Siyi, $\mathrm{OH}$
}


Proc. of SPIE Vol. $113391133901-6$ Downloaded From: https://www.spiedigitallibrary.org/conference-proceedings-of-spie on 26 Apr 2023
Terms of Use: https://www.spiedigitallibrary.org/terms-of-use 


\title{
Conference Committees
}

\author{
Conference Chairs
}

Guangjun Zhang, Southeast University (China)

Byoungho Lee, Seoul National University (Korea, Republic of)

John Greivenkamp, The University of Arizona (United States)

Conference Review Committee

Desheng Jiang, Wuhan University of Technology (China)

Dianyuan Fan, Shenzhen University (China)

Huilin Jiang, Changchun University of Science and Technology (China)

Junhao Chu, Shanghai Institute of Technical Physics, Chinese Academy of Sciences (China)

Jianyu Wang, Chinese Academy of Sciences, Shanghai Branch (China)

Jianquan Yao, Tianjin University (China)

Jiancheng Fang, Beihang University (China)

Jiubin Tan, Harbin Institute of Technology (China)

Lin Li, University of Manchester (United Kingdom)

Lijun Wang, Changchun Institute of Optics, Fine Mechanics and Physics, Chinese Academy of Sciences (China)

Min Gu, University of Shanghai for Science and Technology (China)

Qionghai Dai, Tsinghua University (China)

Shibin Jiang, AdValue Photonics, Inc. (United States)

Shenggang Liu, University of Electronic Science and Technology of China (China)

Shouhuan Zhou, North China Research Institute of Electro-Optics (China)

Toyohiko Yatagai, Utsunomiya University (Japan)

Wenqing Liu, Anhui Institute of Optics and Fine Mechanics, Chinese Academy of Sciences (China)

Wei Wang, Beijing Institute of Aerospace Control Device of CASC (China)

Yueguang Lv, Chinese Academy of Engineering (China)

Zuyan Xu, The Technical Institute of Physics and Chemistry of the Chinese Academy of Sciences (China)

Conference Program Committee

Chaoyang Lu, University of Science and Technology of China (China)

Daoxin Dai, Zhejiang University (China)

Dong Liu, Zhejiang University (China)

Haimei Gong, Shanghai Institute of Technical Physics, Chinese Academy of Sciences (China)

Hongbo Sun, Tsinghua University (China)

Jin Lu, Tianjin Jinhang Institute of Technical Physics (China)

Jinxue Wang, SPIE 
Jin Yu, Shanghai Jiao Tong University (China)

Jian Zhang, Shanghai Institute of Ceramics, Chinese Academy of Sciences (China)

Min Gu, University of Shanghai for Science and Technology (China)

Min Qiu, Westlake University (China)

Michelle Sander, Boston University (United States)

Mengxia Xie, Beijing Normal University (China)

Pu Zhou, National University of Defense Technology (China)

Sven Hofling, Universität Wurzburg (Germany)

Shibin Jiang, AdValue Photonics, Inc. (United States)

Suijian Xue, National Astronomical Observatories, Chinese Academy of Sciences (China)

Takunori Taira, RIKEN SPring-8 Center (Japan)

Vincenzo Palleschi, Institute of Chemistry of Organic Metallic Compounds (Italy)

Wenxue Li, East China Normal University (China)

Xiaocong Yuan, Shenzhen University (China)

Xuejun Zhang, Changchun Institute of Optics, Fine Mechanics and

Physics, Chinese Academy of Sciences (China)

Yadong Jiang, University of Electronic Science and Technology of China (China)

Yongtian Wang, Beijing Institute of Technology (China)

Yuegang Fu, Changchun University of Science and Technology (China)

Zhiping Zhou, Peking University (China)

Zhe Wang, Tsinghua University (China)

Ziyang Zhang, Westlake University (China)

Session Chairs

1 Session 1

Peng Xue, Beijing Computational Science Research Center (China)

2 Session 2

Luke Wilson, University of Sheffield (United Kingdom)

3 Session 3

Val Zwiller, KTH Royal Institute of Technology (Sweden)

$4 \quad$ Session 4

Chaoyang Lu, University of Science and Technology of China (China) 


\section{Introduction}

AOPC 2019, the annual conference of Chinese Society of Optical Engineering (CSOE), was one of the largest academic and industrialization activities in the field of optical and optoelectronic technology in China. The Organizing Committee intended to build a potential platform together with academic exchanges, industry exhibitions, and cooperation negotiations in one. There were 11 technical conferences and 38 conference sessions, and we sincerely hope that the research and development of optoelectronic technology were promoted, and that international cooperation in industry and in the optical and optoelectronic fields were enhanced.

AOPC 2019 was sponsored by SPIE and the Chinese Society for Optical Engineering; the Optical Society of Korea (OSK), Optics and Photonics Society of Singapore (OPSS), European Optical Society (EOS), Optical Society of Japan (OSJ) were the technical co-sponsors. There were also 48 Cooperative Organizations that supported the conference.

We received over 930 total contributions from more than 15 countries, including United States, United Kingdom, Germany, France, Spain, Australia, Canada, Mexico, Brazil, Japan, Republic of Korea, Thailand, Singapore, Russian Federation, China, and so on. There were 554 contributions published in SPIE Proceedings.

After careful discussion, we suggested four keynote speeches which were presented by famous scientists from Germany, Australia, Japan, and China. There were 110 excellent invited talks, 45 of them are from overseas, their inclusion represented a first-class level in the field of optics and photonics technology. On behalf of the Organizing Committee of AOPC, I express thanks to all the invited speakers and authors for their contributions and supports to the conference.

Finally, on behalf of the Chairmen and the Organizing Committee of AOPC, I would like to heartily thank our sponsors and Cooperating Organizations for all they have done for the conference, to all of the participants and friends for their interests and efforts in helping us to make the conference success. Also, thanks to the Program Committee for their effective work and valuable advice; especially the AOPC 2019 Secretariat and SPIE for their tireless effort and outstanding services in preparing the conference and publishing the Proceedings.

We are glad that AOPC 2019 had great success! Hope to see you next year!

Guofan Jin 
Proc. of SPIE Vol. 11339 1133901-10

Downloaded From: https://www.spiedigitallibrary.org/conference-proceedings-of-spie on 26 Apr 2023 Terms of Use: https://www.spiedigitallibrary.org/terms-of-use 